TABLE 1. Personal observation

\begin{tabular}{|c|c|c|c|c|c|}
\hline Patient (age) & Diagnosis & Surgical treatment & Surgical reconstruction & Preoperative FEV $_{1}(\mathrm{~L})$ & 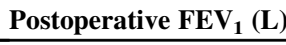 \\
\hline \multicolumn{6}{|l|}{ Group A } \\
\hline $1(47 \mathrm{y})$ & Sarcoma & V, VI, VII & $\mathrm{V}, \mathrm{VI}$ & 2.67 & $2.80(+4.8 \%)$ \\
\hline $2(82 y)$ & Sarcoma & V, VI, VII & $\mathrm{V}, \mathrm{VI}$ & 2.96 & $2.78(-6.1 \%)$ \\
\hline $3(56 y)$ & Metastasis from sarcoma & $\mathrm{V}, \mathrm{VI}$ & $\mathrm{V}$ & 1.31 & $1.25(-4.5 \%)$ \\
\hline $4(58 \mathrm{y})$ & Trauma & VI, VII & VI, VII & 2.10 & $1.99(-5.2 \%)$ \\
\hline $5(71 \mathrm{y})$ & Trauma & IV, V, VI & IV, VI & 1.64 & $1.65(+0.6 \%)$ \\
\hline \multicolumn{6}{|l|}{ Group B } \\
\hline $6(54 y)$ & NSCLC & $\begin{array}{l}\text { Upper lobectomy } \\
\text { (III, IV, V) }\end{array}$ & III, V & 2.49 & $1.97(-20.9 \%)$ \\
\hline $7(48 \mathrm{y})$ & NSCLC & $\begin{array}{l}\text { Upper lobectomy } \\
\text { (III, IV, V) }\end{array}$ & III, V & 2.80 & $1.71(-38.9 \%)$ \\
\hline $8(64 y)$ & NSCLC & (clavicle, I, II, III) & Clavicle, II & 1.42 & $0.98(-30.9 \%)$ \\
\hline $9(56 \mathrm{y})$ & $\begin{array}{c}\text { Malignant pleural } \\
\text { mesothelioma }\end{array}$ & $\begin{array}{l}\text { Left extrapleural } \\
\text { pneumonectomy } \\
\text { (II, III, IV, V, VI) }\end{array}$ & III, IV, VI & 2.61 & $1.36(-47.8 \%)$ \\
\hline \multicolumn{6}{|l|}{ Group C } \\
\hline $10(65 \mathrm{y})$ & Infection & Total sternectomy & Manubrium and sternum & 1.49 & $1.55(-4.0 \%)$ \\
\hline $11(48 \mathrm{y})$ & Renal metastasis & Subtotal sternectomy & Sternum & - & - \\
\hline $12(49 y)$ & Fracture & Partial sternectomy & Sternum & 2.98 & $2.89(-3.0 \%)$ \\
\hline $13(69 y)$ & Fracture & Osteosynthesis & Sternum & - & - \\
\hline
\end{tabular}

Group A, Rib resection; group B, lung and rib resection; group $C$, sternal resection; $N S L C$, non-small cell lung cancer; $F E V_{l}$, forced expiratory volume in 1 second.

\section{References}

1. Bibas BJ, Bibas RA. Operative stabilization of flail chest using a prosthetic mesh and methylmethacrylate. Eur J Cardiothorac Surg. 2006;29:1064-6.

2. Cicilioni OJ Jr, Stieg FH 3rd, Papaniculaou G. Sternal wound reconstruction with transverse plate fixation. Plast Reconstr Surg. 2005;115:1297-303.

3. Voss B, Bauernschmitt R, Will A, et al. Sternal reconstruction with titanium plates in complicated sternal dehiscence. Eur J Cardiothorac Surg. 2008;34:139-45.
4. Lee TY, Estrera AL, Safi HJ, Khalil KG. Total sternal reconstruction using a titanium plate-supported methyl methacrylate sandwich. Ann Thorac Surg. 2007;84: 664-6.

5. Iarussi T, Marolla A, Pardolesi A, Patea RL, Camplese P, Sacco R. Sternectomy and sternum reconstruction for infection after cardiac surgery. Ann Thorac Surg. 2008;86:1680-1.

\title{
Transcatheter valve replacement: Resection and valved stent implantation in a beating heart
}

René Hubert Bombien, MD, ${ }^{\mathrm{a}}$ Lucian Lozonschi, MD, ${ }^{\mathrm{b}}$ Jochen Cremer, MD, PhD, ${ }^{\mathrm{a}}$ and Georg Lutter, MD, $\mathrm{PhD},{ }^{\mathrm{a}}$ Kiel, Germany, and Madison, Wis

During the past 10 years, different models for the transcatheter removal of heart valves have been evaluated. The experiments were performed in different in vitro or in vivo

\footnotetext{
From the Department of Cardiovascular Surgery, ${ }^{a}$ University Hospital SchleswigHolstein, Campus Kiel, Kiel, Germany; and Division of Cardiothoracic Surgery, ${ }^{b}$ University of Wisconsin School of Medicine, Madison, Wis.

Disclosures: None.

Received for publication Nov 2, 2009; accepted for publication Jan 1, 2010; available ahead of print March 26, 2010.

Address for reprints: René Hubert Bombien, MD, Department of Cardiovascular Surgery, University Hospital Schleswig-Holstein, Campus Kiel, Arnold-Heller-Strasse 7, D-24105 Kiel, Germany (E-mail: rbombien@quabo.de).

J Thorac Cardiovasc Surg 2010;140:477-9

$0022-5223 / \$ 36.00$

Copyright (c) 2010 by The American Association for Thoracic Surgery

doi:10.1016/j.jtcvs.2010.01.006
}

models. ${ }^{1-3}$ This report describes a model for complete heart valve replacement with resection before valved stent implantation in a beating heart.

\section{CLINICAL SUMMARY}

The pulmonary valve isolation chamber (PVIC) system was developed to generate an isolated chamber avoiding the escape of debris during the resection process. The system (length, $160 \mathrm{~mm}$;, $30 \mathrm{~F}$ ) consists of 2 balloons: a subvalvular balloon and a supravalvular balloon in the pulmonary artery (Figure 1, $A$ ). The pressures of the balloons were monitored to prevent pressure decreases caused by leakiness. To ensure a clear view during the process, an irrigation flow was established. 




FIGURE 1. A, PVIC prototype with an instrument inlay. B, Experimental setup with an adjustable retaining fixture (\#) stabilizing the PVIC system. Blood was taken from the upper caval vein and piped through the PVIC (arrow) into the pulmonary artery. C, Pulmonary valve leaflet $(*)$ was fixed by the forceps catheter $(* *)$. D, Leaflet $(*)$ being resected and the laser fiber with its aiming beam (arrow). E, Nitinol valved stent was implanted into a supra-annular position (arrow). PVIC, Pulmonary valve isolation chamber; UVC, upper caval vein.

The laser fiber (, $365 \mu \mathrm{m}$; CeramOptec $\mathrm{GmbH}$, Bonn, Germany) was guided by a pseudoelastic microactuator integrated into the rotatable inlay. The forceps catheter $(\varnothing, 1.3 \mathrm{~mm})$ was manually controlled. The visualization (Ø, $0.7 \mathrm{~mm}$; Polydiagnost, Pfaffenhofen, Germany) was realized via the PVIC. The pulmonary valve was resected by a continuous-wave thulium:YAG laser with 20 watts power-rating $(2.01 \mu \mathrm{m}$, ITL Lasergerät SN; 00272001, 380/400V 16 A, Luebeck, Germany).

A radially self-expanding nitinol stent (length, $22 \mathrm{~mm}$; $\varnothing$, $25 \mathrm{~mm}$; Nitinol Devices \& Components, Fremont, Calif) was used. The wires are soft and highly malleable, molding 2 ranks of 14 rhombs each. A porcine aortic valve was sutured into the stent.

The "German Landrace" pig received humane care, as approved by the Center for Experimental Animal Research at Kiel University (V 312-72241.121-6 [48-4/09]) and in compliance with the Guide for the Care and Use of Laboratory Animals, prepared by the Institute of Laboratory Animal Resources, National Research Council, and published by the National Academy Press, revised 1996 (http://www.nap. edu/readingroom/books/labrats/contents.html).

The pig $(60 \mathrm{~kg})$ was premedicated and anesthetized as reported elsewhere. ${ }^{4}$ A venous cannula was placed in the upper caval vein to drain the blood. A double pursestring monofilament suture was placed before the right ventricle was opened. The PVIC was inserted and stabi- lized (Unitrack; BBraun-Aesculap, Tuttlingen, Germany). A blood flow of 3 to $5 \mathrm{~L} / \mathrm{min}$ was established through the PVIC into the pulmonary artery (Figure 1, $B$ ). The chamber balloons were inflated, and the resection was started (Figure 1, $C, D$ ). The leaflets were excised, and the fragments were removed. The valved stent was implanted. The resection process was video controlled and digitally recorded.



FIGURE 2. Hemodynamic data were correlated to the oxygen saturation during the procedure. The arrows indicate the sealing approaches of the pulmonary valve with consecutive resection. MAP, Mean arterial pressure; $\mathrm{SaO}_{2}$, saturation of oxygen. 


\section{RESULTS}

The deployment of the PVIC was easy to perform. The time from skin cut to deployment was 58 minutes. The PVIC installation time was 1 minute, and the sealing was successful.

After the PVIC function was stable, the endoscope offered a clear view to the pulmonary valve (Figure $1, C$ ). The hemodynamics and saturation of oxygen were stable (Figure 2).

The resection of the pulmonary leaflets took 21 minutes and was complete. The PVIC had to be exchanged 4 times because of laser-related damages of the supravalvular balloon.

The deployment of the valved stent took 30 seconds. The stent was deployed in a supra-annular position (Figure 1,E). The gross anatomy of the endomyocardium showed only superficial lesions. All other structures were unaffected.

\section{DISCUSSION}

The feasibility of valve isolation, resection, and implantation of a new valved stent was demonstrated in this beating heart model. The hemodynamic data of the pig were stable during the isolation with only moderate vasopressor administration. The stent was stored in a "parking slot" during the procedure and deployed in a good position. During resection, the supravalvular balloon was injured by the laser 4 times and had to be changed. Nonetheless, the circulatory system was stable after all sealing procedures, but these exchanges explained the extended resection time.

This model was performed in the pulmonary position because of a lower mean blood pressure and the absence of coronary ostia compared with the aortic position. The development of a more complex sealing procedure for the aortic position is in progress.
The transapical insertion of heart valves is presented as a good concept, not only for the well-known aortic position but also for the mitral valve. ${ }^{4}$

In the future it will be important for cardiac surgeons to offer a complete valve replacement to patients according to the gold standard of surgery, especially for highly calcified aortic valves. ${ }^{5}$

\section{CONCLUSIONS}

A complete transcatheter replacement of a heart valve was performed in a beating heart model. This will help to develop further intracardiac surgical procedures, especially the preparation of highly calcified aortic valves before transcatheter valved stent implantations.

The authors thank Jessica Boldt, Wiebke de Buhr, Anja Metzner, Kenji Iino, Martin Marczynski-Bühlow, and Christan Faller. Drs Lutter and Bombien thank their families for support.

\section{References}

1. Salizzoni S, Bajona P, Zehr KJ, Anderson WD, Vandenberghe S, Speziali G. Transapical off-pump removal of the native aortic valve: a proof-of-concept animal study. J Thorac Cardiovasc Surg. 2009;138:468-73.

2. Wendt D, Müller W, Hauck F, Thielmann M, Wendt H, Kipfmüller B, et al. In vitro results of a new minimally invasive aortic valve resecting tool. Eur J Cardiothorac Surg. 2009;35:622-7.

3. Quaden R, Attmann T, Schünke M, Theisen-Kunde D, Cremer J, Lutter G. Percutaneous aortic valve replacement: endovascular resection of human aortic valves in situ. J Thorac Cardiovasc Surg. 2008;135:1081-6.

4. Lozonschi L, Quaden R, Edwards NM, Cremer J, Lutter G. Transapical mitral valved stent implantation. Ann Thorac Surg. 2008;86:745-8.

5. Bombien R, Hümme T, Schünke M, Lutter G. Percutaneous aortic valve replacement: computed tomography scan after valved stent implantation in human cadave hearts. Eur J Cardiothorac Surg. 2009;36:592-4.

\title{
One-stage repair for interrupted aortic arch and associated cardiac anomalies in an adult
}

\author{
Zhang Jinzhou, MD, ${ }^{\mathrm{a}}$ Wang Wen, MD, ${ }^{\mathrm{b}}$ Zhu Hailong, MD, ${ }^{\mathrm{a}}$ and Wang Hongbing, MD, ${ }^{\mathrm{a}}$ Xi'an, People's \\ Republic of China
}

\footnotetext{
From the Departments of Cardiovascular Surgery ${ }^{\mathrm{a}}$ and Traditional Chinese Medicine, Xijing Hospital, the Fourth Military Medical University, Xi'an, People's Republic of China.

Disclosures: None.

Zhang Jinzhou and Wang Wen contributed equally to this work.

Received for publication Nov 4, 2009; accepted for publication Jan 1, 2010; available ahead of print March 26, 2010.

Address for reprints: Zhang Jinzhou, MD, and Wang Hongbing, MD, Department of Cardiovascular Surgery, Xijing Hospital, the Fourth Military Medical University, Xi'an (710032), People's Republic of China (E-mail: jinzhouzhang2006@yahoo. com; ailisr@yahoo.com.cn).

J Thorac Cardiovasc Surg 2010;140:479-81

$0022-5223 / \$ 36.00$

Copyright (c) 2010 by The American Association for Thoracic Surgery

doi:10.1016/j.jtcvs.2010.01.008
}

For infants with interrupted aortic arch (IAA) and associated cardiac malformation, 1-stage repair is preferred, and excellent results have been reported. ${ }^{1}$ However, similar experiences in adult patients are limited because of the rarity of the condition. We report a woman with IAA and associated cardiac malformations who was treated surgically by 1 -stage repair.

\section{CLINICAL SUMMARY}

A 21-year-old woman was admitted for congenital heart murmur. Echocardiography revealed a subpulmonary 